\title{
Investigating social support patterns of single mothers from a social network perspective
}

DOI 10.1515/irsr-2016-0021

Received: March 4, 2016; Accepted: June 27, 2016

\begin{abstract}
In the present study, we discuss how social network analysis approach can be fruitful exploited to study social support within family studies. An ego-centred network approach is adopted within a case study about social support networks of low income single mothers living in a city of southern Italy. We address three main issues. First, we aim to describe and explore the structure of social relationships that single mothers activate in order to obtain different kind of supports. Second, we investigate the main factors that affect the amount and variety of resources embedded in the single mothers' support networks. Third, we analyse the relationship between the received social support embedded in the ego network and the support perceived by mothers. Beyond the description of composition and structure of egocentred networks through network measures and factorial methods, a series of regression models was estimated to assess factors explaining received and perceived support of single mothers.
\end{abstract}

Keywords: Social support, Single motherhood, Egocentred network analysis, Multidimensional Data Analysis

\section{Introduction}

Social support is a complex, dynamic and multidimensional concept, partially overlapping with social relationships. Its conceptual domain includes both the structural apparatus under which supportive transactions take place and the types of resources embedded in and accessible through social relationships (Lin, 2002). This is what O'Reilly (1988) speaks about when he discusses the difference between two dimensions

*Corresponding author: Maria Prosperina Vitale, University of Salerno, Italy, E-mail address: mvitale@unisa.it

Rosaria Lumino, Giancarlo Ragozini, University of Naples, Italy underpinning social relationships: the structure and the function. The former refers to the type of individuals linked by a certain type of tie in a network and the frequency of contacts among them. The latter refers to the content of resources and influences flowing across the ties and covers the qualitative and behavioural aspects of social relationships (Due et al., 1999). Thus, social relations' function could be considered equivalent to social support, which, as such, expresses the mutuality and the affection characteristics of the social relationships that social support arises from. In general terms, close relationships often provide a wider range of types of support than casual acquaintances, whereas formal relationships that are more strictly defined by normative roles tend to offer more specialised kinds of support (Gottlieb and Bergen, 2010).

Social support may also be specified according to the types of aid flowing through social relationships, grouped in four major categories: instrumental support referring to aid, assistance or help for the fulfilment of ordinary responsibilities (childcare, household related obligations, help for shopping, borrowing money); emotional support providing empathy, sympathy, opportunities for discussing personal matters and so forth; informational support related to the provision of advice and information for particular needs (job opportunities, available services); and social companionship providing opportunities for sociability, such as getting together with friends (Vaux, 1988).

Of additional note is the distinction between the actual or enacted support and the subjective appraisal of its availability, in other words the "perceived social support" related to personal expectations about the willingness of others to provide support. Empirical evidence suggests reciprocal influence processes between the two terms, even though their relationship is far from being linear. The perceived social support is, in fact, also affected by personality traits, such as self-confidence, and subjective beliefs (Gregory et al., 1996).

The multidimensional nature of social support has often been at the core of the ambiguous conceptualisations 
in scholarship's long-standing interest in the topic, especially with regard to the overlap between social support and social networks (namely personal networks), that is, between the function and the structure of social relationships, already mentioned. This is not merely a semantic matter, because it has relevant implications on an empirical ground.

As widely known, social network analysis (SNA) approach (Wasserman and Faust, 1994) focuses on the properties social relationships' patterns among actors rather than on the characteristics of actors themselves, by assuming that "networks have emergent properties, not explained by their constituent parts and not present in the parts", which can be more adequately analysed by seeing whole groups of parts and their interconnections as a whole (Smith and Christakis, 2008: 407-408). This applies both to whole networks and to egocentric ones, as in the case of social support.

Within social support studies, SNA affords an advantage point for providing information about the structural properties of social relationships, involving the quantitative account of connections in terms of the numbers of ties, their density or interconnectedness, and other measures of linkage between people, as well as for understanding how the structure of relationships might influence individual behaviours by shaping the flow of resources which determine access to opportunities and constraints on behaviour (Berkman et al., 2000).

On these premises, we have chosen the ego-centred network approach (Wellman, 2007) to analyse the pattern of relationships on which social support networks are based. Here, the case of single mothers is considered: the provision of social support through personal networks is, for them, more relevant than for other types of families, as single mothers are more exposed to hardship and social exclusion. Specifically, within a case study, we address three main issues in order to: $i$ ) describe and explore the structure of social relationships that single mothers activate in order to obtain different kind of supports; ii) investigate the main factors that affect the amount and variety of resources embedded in the single mothers' support networks; and iii) analyse the relationship between the received social support embedded in the ego network and the support perceived by single mothers.

The paper is organized as follow: first, we present a brief review of studies on social support based on SNA approach, highlighting some important gaps, especially in the field of parenting studies. The relevance of supportive networks for single mothers is consecutively discussed. Then, we provide details on the case study with a focus on the research participants, the procedure, the adopted statistical methods, and the survey instruments. Finally, the main results are discussed along with a reflection on future lines of research.

\section{Social support and social networks}

Since the 70s and 80s, the interest in social support has prompted several studies mainly devoted to the analysis, on the one hand, of the indirect effects of personal supportive networks on health and wellbeing and, on the other hand, of the association between social support and social integration.

Studies about the effects of social networks on health can be traced back to the seminal works of Cassel (1976), Cobb (1976) and Berkman (1986) who theorised or demonstrated empirically that social networks could affect comorbility and mortality. From that point on, many studies have focused on how health behaviours are spread or constrained by network dynamics as well as on how social support provision affects mental and physical health (see Smith and Christakis, 2008; Stansfeld and Khatib, 2011).

These studies, focusing on social networks and social integration, have stressed the role of social relationships in coping with the risks and difficulties of daily life and in promoting social inclusion, especially in adverse conditions. They generally fall inside the broad research agenda on social capital and analyse how the structural aspects of individual social positions affect the access to several kinds of resources, including social support and material goods, which foster social integration and upward social mobility opportunities.

For our purposes, the studies on family poverty are considered. They point out that social networks have important implications for families' wellbeing as well as for defining successful coping strategies (Eckenrode and Hamilton, 2000). In fact, social support is one of the main ways through which families obtain resources to deal with daily life, seize opportunities and reduce uncertainty (Tietjen, 1985; Henly et al., 2005), especially when potentially stressful events occur, such as single motherhood (Cohen and Wills, 1985). The key contribution of a supportive environment to children's social development has also been highlighted (e.g., Symonds, 1939 and Rollins and Thomas, 1979 as early pioneers in this field of study).

Despite the large body of research on social support, some important gaps in the literature have been noted, especially in the field of parenting studies. Following Geens and Vandenbroeck (2014), social support has been 
often analysed in relation to parental health as a buffer against potential negative outcomes for children. On the contrary, less attention has been given to the relational aspects of social support and to the many possible interactions between a diversity of people as relevant sources of support in the everyday parenting process. In addition, several contributions emphasise the qualitative aspects of social relationships rather than quantitative ones, by "metaphorically" using the network concept instead of applying SNA methods for data collection and data analysis (Berckman et al., 2000).

At any rate, within the SNA literature, it is possible to find studies on this topic mainly concentrated in areas related to mental health and wellbeing as well as specialised subfields focusing on, for example, the quality of social support measurement instruments using egocentred network approach (e.g. Agneessens et al., 2006; Hlebec et al., 2012; Hlebec and Kogovšek, 2013).

\section{Single mothers and family support}

In such a context, single mothers represent an interesting target of study. Even if being a single parent does not in itself predicate a condition of need, there is broad consensus among researchers that single parents are more vulnerable to poverty and social exclusion, especially when they have dependent children (Fouarge and Layte, 2005). Indeed, the percentage of single parents at risk of poverty is $24.4 \%$ on average, ranging from $28.0 \%$ in the Nordic countries to $30.3 \%$ in the Mediterranean area (Eurostat, 2015). Thus, the provision of social support through personal networks plays a crucial role in furnishing resources and in generating opportunities to share problem-solving and to help with arrangements for coping with daily life.

The number of single-parent households has increased steadily across all European countries over the past decades, accounting for almost $8 \%$ of all European households (Iacovou and Skew, 2011), but this figure underestimates their number as a proportion of singleparent families shares accommodations with another household, especially in southern Europe (around 2\% in all Europe and specifically 4\% in the Mediterranean area - Eurostat, 2013).

Although single parents are increasingly diverse in terms of age, gender, ethnic group and sexual orientation (Ruspini, 2011), women still represent over $80 \%$. This implies that the potential condition of hardship associated with single parenthood is worsened by chronic female disadvantage in the European labour market, especially in the southern countries. Here, the life conditions of single mothers are also penalised by both the low accessibility of social service provisions and the persistence of traditional models underpinning the division of domestic tasks. As a result, the family is too often a burden that women tend to shoulder on their own, making women more vulnerable (Saraceno, 2002). Indeed, according to Ranci (2012: 271-272), "social vulnerability is greater where a work/ childcare balance is not achieved and a gendered division persists between domestic work and employment in the labour market”.

For these reasons, family support often represents a key source (often the only one) for single mothers' survival strategies (Stack, 1975; Belle, 1982), although the worsening of life conditions as well as the crisis of welfare state are intensifying the pressure on family systems so much so that compromise their ability to collect and redistribute resources for the benefit of their weakest members (Ranci, 2012). Notwithstanding, family still represents one of the most important risk-management and risk-coping options in providing social support and in compensating for the deficiencies of the welfare state (Naldini, 2003).

\section{The present study}

If the redistributive role of the family has been particularly important in all European Mediterranean countries, Naples (in southern Italy) represents an extreme case. Naples has been historically characterised by a chronic inability of the local welfare system to satisfy residents' needs (Morlicchio, 2005). Here, the family acts as the primary welfare unit, within an institutional context of reduced development of family policies, in which the main source of social rights is derived from paid work. This pattern is closely interwoven with the structure of the labour market, which discourages women's participation in the work force and with high incidences of both poverty and low schooling, especially for young women. In the absence of an adequate welfare system, income support schemes or employment opportunities, family and kinship networks are mobilised. The result is a "forced familism" (Gambardella and Morlicchio, 2005) pursued in a coherent way as a survival strategy, within a specific structure of opportunities and constraints. This situation has been described in terms of "integration into precariousness", in which the family members are able to solve their daily problems through a combination of kinship and family support and odd jobs in order to maintain a more or less precarious equilibrium (Morlicchio, 2005, p. 286). Accordingly, single mothers living in Naples can rely on 
informal resources as a result of family solidarity, not present elsewhere. However, here social support is often provided by other family members who have little to offer, because they are only marginally connected with the labour market, and they are also poor.

In the present paper, we address three main issues. First, we aim to describe and explore the structure of social relationships that single mothers activate in order to obtain different kind of supports. Second, we investigate the main factors that affect the amount and variety of resources embedded in the single mothers' support networks. Third, we analyse the relationship between the received social support embedded in the ego network and the support perceived by mothers.

\section{Participants}

A total of 35 women were interviewed during 2013. The study participants share a similar family and economic background, characterised by low skill levels (at most they obtained the eighth grade, that is the final grade of compulsory school in Italy), irregular jobs and inadequate income.

The average age of participants is 39 (with the standard deviation equal to 9.1 years), with a prevalence of women aged between 35 and 55 years (24). Regarding marital status, 11 mothers are separated, 9 widowed and the remaining 12 unmarried. Only three of the women have a new partner. The duration of single parenthood is 8 years on average.

Slightly less than half of the women live with their parents, while 17 live alone with their children. They have two children on average, while three of the mothers have more than three children. Their children are around 9 years old (median), ranging from one year to 17 . Twentyfive of the women work, even if, in half of the cases, they have irregular jobs.

\section{Procedure}

In-depth interviews were chosen as the main research method, together with a brief questionnaire using a network generator approach to reconstruct single mothers' personal networks (Marsden, 2011). We tested the instruments by interviewing five single mothers. We add some concrete examples of different kinds of social support in name generators in order to make clearer the differences among supports.

Due to the restrictions on the access to the local administrative database with a complete list of low income single mothers, women were recruited with the assistance of social services offices as well as non-profit organisations. Three selection criteria were applied: $i$ ) to have been a single parent for at least two years, ii) to be the legal guardian of at least one child under the age of majority (18 years), and iii) to have a low income.

\section{Instruments}

In order to describe the social support patterns embedded in the single mothers' networks, we adopt an ego-centred network approach, and we investigate the received social support by using a name generator to derive their networks. Specifically, a multiple name generator with five questions was used to measure social support networks according to the main support dimensions: instrumental, informational, social companionship and emotional (Kogovšek et al., 2002). In particular, given the poverty condition of our context, we decided to separately investigate the financial aid aspect, which is usually included within instrumental support. Thus, we administrated two questions: one specific for pure instrumental support, consisting of the fulfilment of ordinary tasks, and one regarding financial support, related to the lending/borrowing of small amounts of money.

For each name generator, the respondent could point out five people (referred to as alteri in the following), allowing 25 alteri at maximum. A name interpreter was then used to define the characteristics of each alter in terms of sex, age, educational level and job position as well as the ties' properties of ego-alter relations and alterby-alter connections. Each single mother (referred to as ego in the following) was asked to report for each alter: the type of relationship (i.e., parents, siblings, friends, workmates, etc.), the duration of the relationship in years, the frequency of contact on a 6-point scale (from "every day" to "less than once a year"), the feelings of closeness on a 4-point scale (from 1 "very far" to 4 "very close") and the feelings of importance on a 4-point scale (from 1 "not important" to 4 "very important").

Finally, in order to reconstruct the alter-by-alter relationships, we required that single mothers indicate the relationships among their alteri.

In order to measure the perceived support, we used the Multidimensional Scale of Perceived Social Support (MSPSS) by Zimet et al. (1988). The scale consists of three subscales that provide a self-report measure of perceived adequacy of social support. The three subscales are related to the roles played by friends, family and a significant other, that is a special person to whom the ego feels particularly close. The three subscales are then 
summarised in order to obtain one measure of the global perceived support. Responses were measured on 5-point Likert scale (where 1 is "very strongly disagree" and 5 "very strongly agree").

In the current study, the Cronbach's alpha coefficients are $0.88,0.75$ and 0.71 for the three subscales and 0.91 for the global measure. Such values denote a very good reliability of the MSPSS.

\section{Statistical analysis}

With respect to the first aim, that is, exploring social support patterns, thanks to the name generators, name interpreter and alter-by-alter relationships, we collected information about both the structure of the single mothers' social support networks and the function in terms of received support. We adopt network measures for the analysis of ego-centred network in terms of size, composition and structure as well as multivariate statistical methods to map the relationship between the networks structure and the contents of the provided supports.

Specifically, some measures are used in the analysis of ego network data (for a review see Borgatti et al., 2013: 271), such as network size (i.e. the number of alteri connected with ego) and density (i.e. the percentage of observed connections among alteri out of the number of possible ties). In addition, the Blau's heterogeneity index -BHI- and its normalized version introduced by Agresti (the Index of qualitative variation - IQV) are computed to describe alteri heterogeneity looking at their distribution across categorical attributes (e.g., gender, age and job position), and the E-I index (Krackhardt and Stern, 1988) to measure ego-alter similarity that reflects homophily behaviours in choosing similar others (e.g., alteri are females, with the same age and job position of single mothers). Alteri heterogeneity can be consider a measure of the variety of resources that ego can mobilized in the network, while the gender and age homophily could provide information about gender segregation and intergenerational trait of the ego-networks. In addition, among the measures introduced by Burt (1992) to highlight the ego's brokerage opportunities in an open structure with multiple structural holes, we consider effective size (i.e., the number of alteri that the ego has minus the average number of ties that each alter has to other alteri), and the efficiency (i.e., the effective size out of the network size). These networkderived measures are included as explanatory variables in the regression models estimated to measure the factor influencing the received support of single mothers.

To map the relationship between the structure of the ego-centred networks and the functional aspects of provided supports, we perform a Multiple Correspondence Analysis (MCA) (Greenacre and Blasius, 2006). MCA can be considered a generalisation of the simple Correspondence Analysis aiming at describing and exploring the association patterns among a set of more than two categorical variables. The technique is commonly used to graphically explore patterns in questionnaire responses by looking at factorial maps (usually two-dimensional maps). In these maps, all the variable categories are represented, it is possible to analyse their associations looking at angles and distances among the categories: short distances and angles point out strong associations. Here, we use this technique to find association patterns in ego networks by considering alteri as statistical units. For each alter, the socio-demographic characteristics (sex, age and job position), the type of relationship with the ego and the strength of ties are the variables describing the network structure, and the types of support offered from different alteri to egos are considered for the functional content. In this way, we are able to jointly analyse the relation among alteri characteristics, their role in the social support networks and the kinds of support provided.

With respect to the second aim, i.e. identifying the factors that affect the available social support resources, we perform a set of regression analyses relating the network-derived measures with the ego's characteristics, her family and her loneliness experience. More specifically, we consider the following as response variables: the network size as a proxy for the amount of available and achievable resources of social support for single mothers, and the effective size as a measure of the opportunities for egos in the presence of structural holes. As explanatory variables, we consider the age of the single mothers, the number of children and the age of the youngest one as well as the duration of single parenthood and their living conditions. Other single mother characteristics have not been considered here, as they are homogenous or not relevant at all.

Finally, in order to analyse the relationship between the received social support embedded in the ego network and the support perceived by single mothers (third aim), we perform four regression analyses, one for each of the three subscales and one for the global perceived support of the MSPSS. The ego characteristics, along with the network composition, the types of support that alteri provide to egos and network-derived measures have been used as predictors. The network characteristics are assumed as a proxy for the actual support received. To identify for each model the relevant explanatory variables, we use an automatic backward selection (see 
e.g. Miller, 1984). In all the previous regression models, we test also for the presence of interaction effects between predictors.

\section{Results}

The ego-centred networks reconstructed for the 35 single mothers are described through network measures computed by using the E-net software (Borgatti, 2006; Halgin and Borgatti, 2012). The relationships linking ego to alteri are analysed using the afore mentioned factorial methods. Finally, a series of multiple regression models is estimated to underpin the predictors that explain both the network size and effective size of ego-centred networks and the perceived support of single mothers.

\section{Composition and structure of ego-centred networks}

The single mothers reported in total 184 alteri for the five dimensions of the social support networks. The average size of network is 5 alteri, ranging from 3 to 12 alteri. In small size ego networks, alteri referred mainly to relatives. When the network size increases, single mothers receive support from friends, workmates or social workers. Generally, connections with family members predominate
( $48.4 \%$ of alteri), even if the presence of friends is also relevant (35.3\%).

Figure 1 provides four examples of ego-centred networks: they are characterized by two network sizes, small vs large, and by two conditions for structural holes opportunities. These ego networks display representative configurations, useful to summarise our findings. The first two cases (Figure 1a; Figure 1b) represent small networks unable to give any substantial support due to the joint effect of the quantitative and qualitative inadequacy of the network members. A high level of homophily related to gender and low heterogeneity due to the prevalence of kinship ties characterises this kind of relation patterns. Some quotations from single mother interviews can be here recalled for illustrative purpose.

\begin{abstract}
«Everyone has got their own problems, specifically economic ones. We all are on the same boat, none of us can help the other. At the most, we help each other for little, ordinary things».

«Who helps me seriously? Nobody. I have three sisters, but they can't help me. No one regularly works. They make do as best they can. Two of them are single mothers, too. [...] I can't ask them for anything [...] We can only spend our free time all together or let off steam each other».
\end{abstract}

The second part of the figure (Figure 1c; Figure 1d) shows larger and more heterogeneous networks, where supportive a)

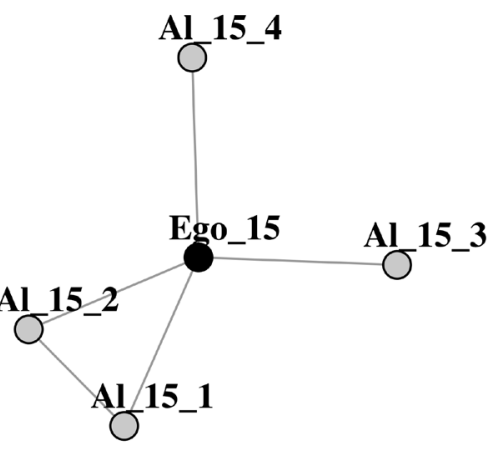

C)

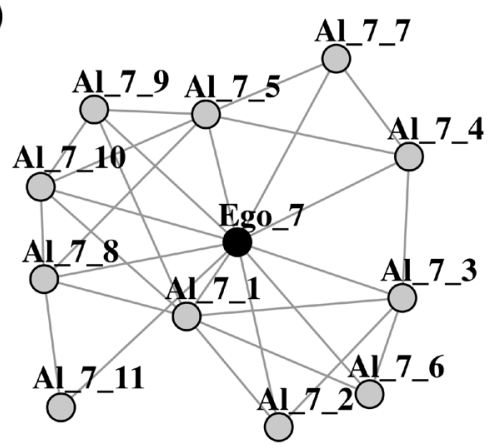

b)

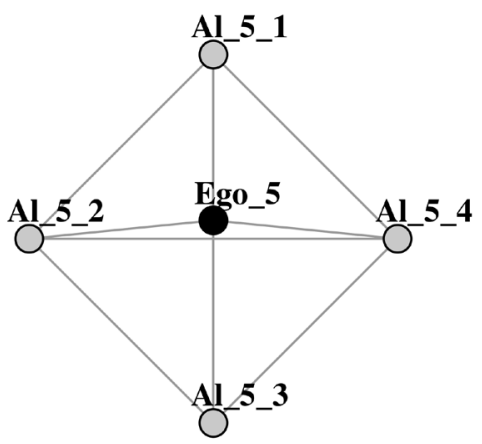

d)

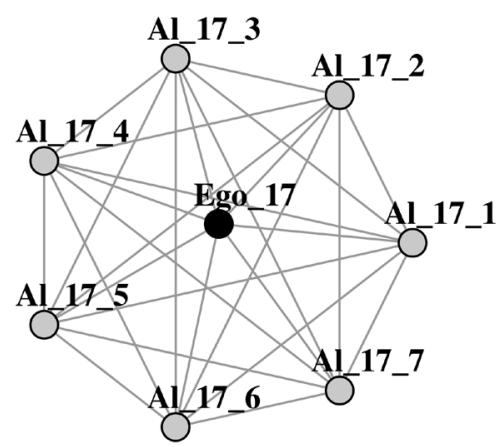

Figure 1. Four examples of ego-centred networks with ego at the centre of the graph. Nodes' color: egos (black), alteri (grey). a) and c): small and large network size with high ego's efficiency value; b) and d): small and large network with low ego's efficiency value. 
relationships are provided by different kinds of alteri who play a crucial role in making adjustments to cope with daily life. However, they cannot help single mothers to improve their lives or to set up active routes out of poverty, because they often share similar conditions of hardship.

«Yes, I am not alone, I have my family and some friends [...] they give me help in bearing my younger child, they listen me when I have a problem, they give me advices [...] we spend much time together [...] for the rest they can't help me, they are as badly off as me».

«Thanks to my parents, when I got pregnant and also afterword, I have not lost my friends, I went out with my friends and they are still with me when I have a problem. We help each other's even if we are all in trouble»

In addition, two single mothers (Figure $1 \mathrm{~b}$ and Figure 1d) seem embedded in their support networks in which alteri are connected each other; instead the others play a brokerage role in a network where alteri are unconnected (Figure 1a and Figure 1c).

The ego networks are analysed in terms of alteri composition with whom ego interacts according to their characteristics (gender, age, job position, type and duration of relation linking ego to alteri, and the type of support provided).

The single mothers receive support mostly from other women, who represent $70.1 \%$ of all mentioned alteri. This leads to a high homophily with respect to gender (E-I index $=-0.40$ at the network level) and low values of heterogeneity indices $(\mathrm{BHI}=0.32, \mathrm{IQV}=0.65)$. However, there are some exceptions especially in larger ego networks, where participants acknowledged support provided by men.

With respect to age, we observe a high level of heterogeneity $(\mathrm{BHI}=0.75, \mathrm{IQV}=0.98)$ and low homophily (E-I index $=-0.08$ at the network level). This aspect characterises the networks as intergenerational support networks combining parents and grandparents, sibling and peers and children.

Around $60 \%$ of alteri has a job, while $24.0 \%$ is represented by housewives, showing larger values of heterogeneity $(\mathrm{BHI}=0.58, \mathrm{IQV}=0.90)$ and a heterophily behaviour (E-I index $=0.45$ at the network level).

The relationships are deep in the sense that they are mainly long term and frequent: single mothers have strong relationships with alteri over periods of five years or more $(82.1 \%)$ with daily contacts $(53.3 \%)$ or contact several times a week $(26.6 \%)$. They feel very close to more than half of the alteri (58.2\%) and consider these relationships to be very important in their lives (64.7\%).

Table 1 shows the type of relationship linking egos to alteri according to the provided social support. Alteri furnish mainly social companionship and instrumental support, and they have specialised functions. Friends are mostly involved in social companionship and emotional support, while mothers and relatives supply instrumental support. Mothers, fathers and siblings aid egos by lending small amounts of money, and social workers and friends serve as a good source of informational support. In general, friends, mothers and other relatives constitute the main sources of support for single mothers, even if they offer at most two types of support for each one. Support networks

Table 1. Composition of received social supports from different kinds of alteri relations with egos (frequencies). Total= \# of alteri for each type of support. Each alter could be mentioned by ego from different kind of supports.

\begin{tabular}{|c|c|c|c|c|c|}
\hline & Instrumental & Informational & Social Companionship & Emotional & Financial \\
\hline Ex-partner & 2 & 1 & 0 & 0 & 2 \\
\hline Father & 3 & 2 & 1 & 1 & 8 \\
\hline Friend & 13 & 11 & 49 & 24 & 6 \\
\hline Mother & 15 & 2 & 3 & 3 & 10 \\
\hline Neighbour & 2 & 0 & 3 & 1 & 1 \\
\hline New partner & 1 & 0 & 2 & 1 & 0 \\
\hline Relative & 11 & 8 & 17 & 7 & 6 \\
\hline Sibling & 11 & 5 & 9 & 12 & 13 \\
\hline Social worker & 2 & 10 & 0 & 4 & 0 \\
\hline Son/daughter & 2 & 0 & 2 & 0 & 3 \\
\hline Workmate & 0 & 2 & 2 & 0 & 3 \\
\hline Total & 62 & 41 & 88 & 53 & 52 \\
\hline
\end{tabular}


are very dense ( 0.37 on average) and are characterised by redundant links among alteri - the effect size is 2.14 and the efficiency value is equal to 0.42 . Thus, the majority of single mothers are embedded in their support networks in which alteri are connected each other. Only few of them gain brokerage advantages by being linked to unconnected alteri (non-redundant information).

In addition, to map the relationship between the network structure and the functional content of supports provided by the 184 alteri, a Multiple Correspondence Analysis is performed. The factorial map (Figure 2) shows on the first factorial axis the opposition of fathers (left) and friends (right). Fathers are associated to the retired condition and in the direction of financial support and opposite to social companionship. Near to the fathers, we found mothers (bottom left) associated to the housewife condition and in the direction of instrumental support. In the same direction, but closer to the origin of the axes, we found siblings (mainly sisters). Thus, the third quarter represents the area of the global instrumental support associated to kinship support. On the right side, we observed the social and emotional support provided by friends, and we also found the youngest class of alteri, students and unemployed people. Near to emotional support we also found the new partners present in the observed networks and the oldest sons of single mothers. Finally, in the upper left side of the map, we observed informational support strongly related to the presence of social workers and workmates.

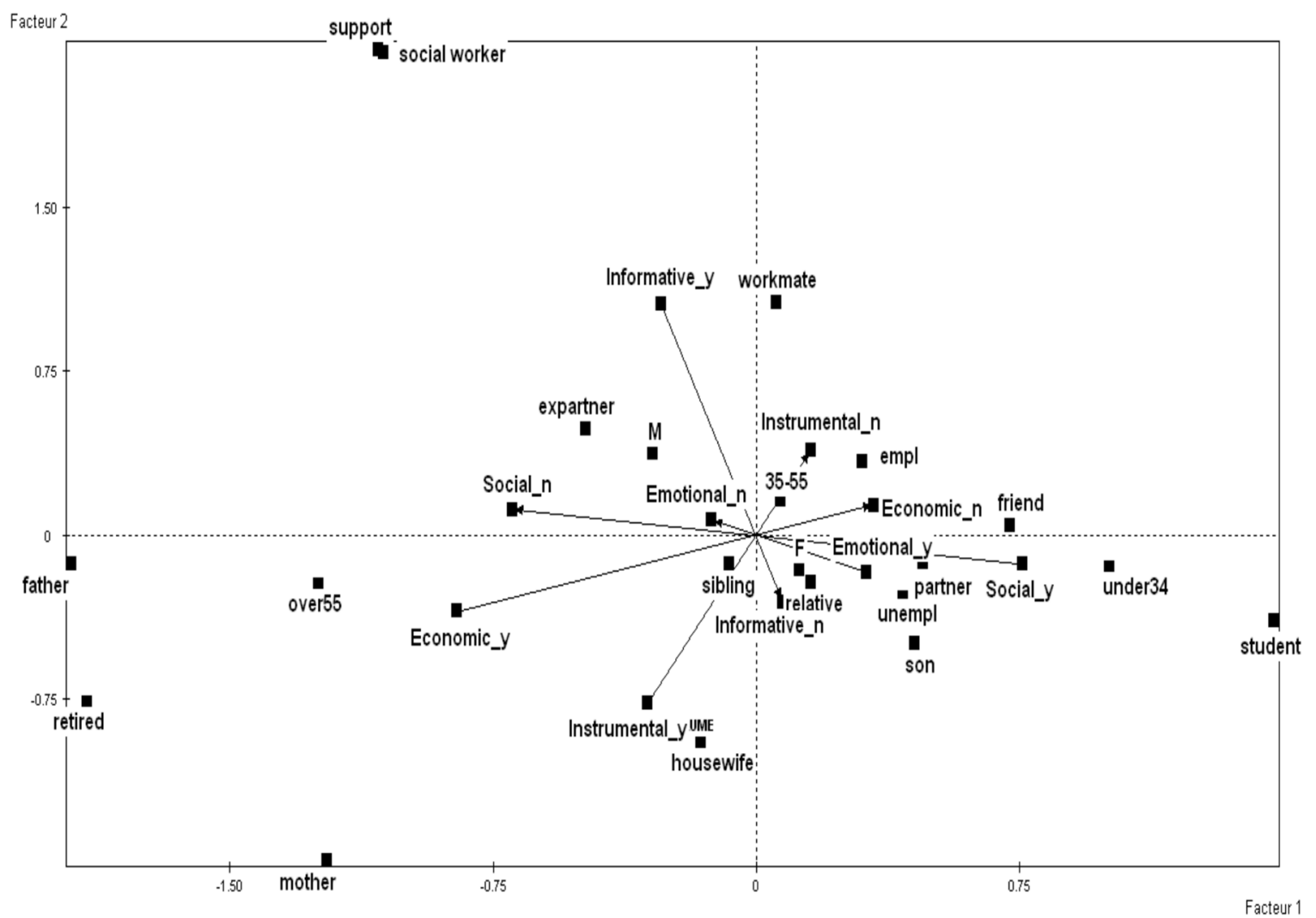

Figure 2. Factorial map with types of support and socio-demographic characteristics of alteri.

Table 2. Main characteristics of predictors entered into the regression models with network size and effective size as response variables.

\begin{tabular}{lllr}
\hline Variable & Label & Type & Average (St.Dev.) \\
\hline Age & Age & Continuous & $38.7(9.2)$ \\
Number of children & NChild & Discrete & $2.1(1.2)$ \\
Age of the youngest child & AgeYChild & Continuous & $8.7(4.6)$ \\
Duration of single parenthood (in years) & DurationP & Discrete & $7.8(5.1)$ \\
Condition of living with parents & LivingP & Categorical (dummy) & $45.7 \%($ yes) \\
\hline
\end{tabular}




\section{Explaining single mothers' social support networks}

A series of multiple linear regression models was estimated to determine the factors that explain single mothers' social support networks. A backward regression procedure was used considering, first, all possible explanatory variables in the model and then deleting variables with the smallest change in the $\mathrm{R}^{2}$ coefficient.

The variables described in Table 2 were inserted into the models $\left(M_{1}-M_{5}\right)$ as predictors of network size and effective size. In addition, an interaction term between age and living condition is included.
The estimated models (Table 3) suggest that the duration of single parenthood and living with parents have a positive effect on network size $\left(\mathrm{M}_{2}-\mathrm{M}_{5}\right)$. Specifically, mothers who are single for a longer period of time or who live with their parents have larger support networks: being a single for a longer period, they are better able to cope with this condition. Enlarging their networks, as well as living with parents, enables single mothers to have more supporting people in their network. The number of children has a negative effect, even if it has a significant coefficient only in model $3\left(\mathrm{M}_{3}\right)$.

When considering the effect of these variables on effective size, there is a positive effect of living with

Table 3. Estimated multiple regression models (M1-M5). Estimated coefficients, their standard errors (in italic), $\mathrm{R}^{2}$ coefficient for the estimated models. Response variables: Network size and Effective size. Labels: age [Age]; number of children [Nchild]; age of the youngest child [AgeYChild]; duration of single parenthood [DurationP]; living with parents [LivingP]. Significant coefficients are marked by: ${ }^{*} \mathrm{p}<0: 10$, ${ }^{\star \star} p<0: 05,{ }^{* \star *} p<0: 01$

\begin{tabular}{|c|c|c|c|c|c|}
\hline & $M_{1}$ & $M_{2}$ & $M_{3}$ & $M_{4}$ & $M_{5}$ \\
\hline \multicolumn{6}{|l|}{ Network size } \\
\hline \multirow[t]{2}{*}{ Constant } & 2.47 & $4.19^{\star \star \star}$ & $4.41^{\star \star \star}$ & $3.75^{\star \star \star}$ & $2.94^{\star \star \star}$ \\
\hline & 3.15 & 1.08 & 1.03 & 0.89 & 0.77 \\
\hline \multirow[t]{2}{*}{ Age } & 0.04 & & & & \\
\hline & 0.06 & & & & \\
\hline \multirow[t]{2}{*}{ Nchild } & -0.43 & -0.44 & $-0.51^{\star}$ & -0.48 & \\
\hline & 0.31 & 0.30 & 0.29 & 0.29 & \\
\hline \multirow[t]{2}{*}{ AgeYChild } & -0.03 & -0.04 & -0.04 & & \\
\hline & 0.03 & 0.03 & 0.03 & & \\
\hline \multirow[t]{2}{*}{ DurationP } & $0.16^{\star \star}$ & $0.15^{\star \star}$ & $0.14^{\star \star}$ & $0.16^{\star \star}$ & $0.12^{\star}$ \\
\hline & 0.07 & 0.07 & 0.07 & 0.07 & 0.07 \\
\hline \multirow[t]{2}{*}{ LivingP } & 5.80 & $4.18^{\star \star}$ & $2.66^{\star \star}$ & $2.76^{\star \star \star}$ & $2.95^{\star \star \star}$ \\
\hline & 3.47 & 2.06 & 0.65 & 0.65 & 0.66 \\
\hline \multirow[t]{2}{*}{ Age ${ }^{\star}$ LivingP } & -0.08 & -0.04 & & & \\
\hline & 0.08 & 0.06 & & & \\
\hline $\mathbf{R}^{2}$ & 0.48 & 0.48 & 0.46 & 0.44 & 0.39 \\
\hline \multicolumn{6}{|l|}{ Effective size } \\
\hline \multirow[t]{2}{*}{ Constant } & 39.30 & 15.79 & 112.13 & 74.95 & \\
\hline & 231.97 & 205.17 & 68.77 & 55.10 & \\
\hline \multirow[t]{2}{*}{ Age } & 1.81 & 2.13 & & & \\
\hline & 4.55 & 4.27 & & & \\
\hline \multirow[t]{2}{*}{ Nchild } & -19.70 & -19.25 & -19.81 & & \\
\hline & 22.57 & 22.11 & 21.80 & & \\
\hline \multirow[t]{2}{*}{ AgeYChild } & -0.54 & & & & \\
\hline & 2.33 & & & & \\
\hline \multirow[t]{2}{*}{ DurationP } & $12.31^{\star \star}$ & $12.56^{\star \star}$ & $12.19^{\star \star}$ & $11.07^{\star \star}$ & \\
\hline & 5.34 & 5.15 & 5.03 & 4.86 & \\
\hline \multirow[t]{2}{*}{ LivingP } & 398.17 & 410.77 & $313.97^{\star \star}$ & $360.86^{\star *}$ & \\
\hline & 255.31 & 245.35 & 148.43 & 138.78 & \\
\hline \multirow[t]{2}{*}{ Age ${ }^{\star}$ LivingP } & -8.24 & -8.48 & -6.24 & $-7.36^{\star}$ & \\
\hline & 6.21 & 6.03 & 3.97 & 3.76 & \\
\hline $\mathbf{R}^{2}$ & 0.28 & 0.27 & 0.27 & 0.25 & \\
\hline
\end{tabular}




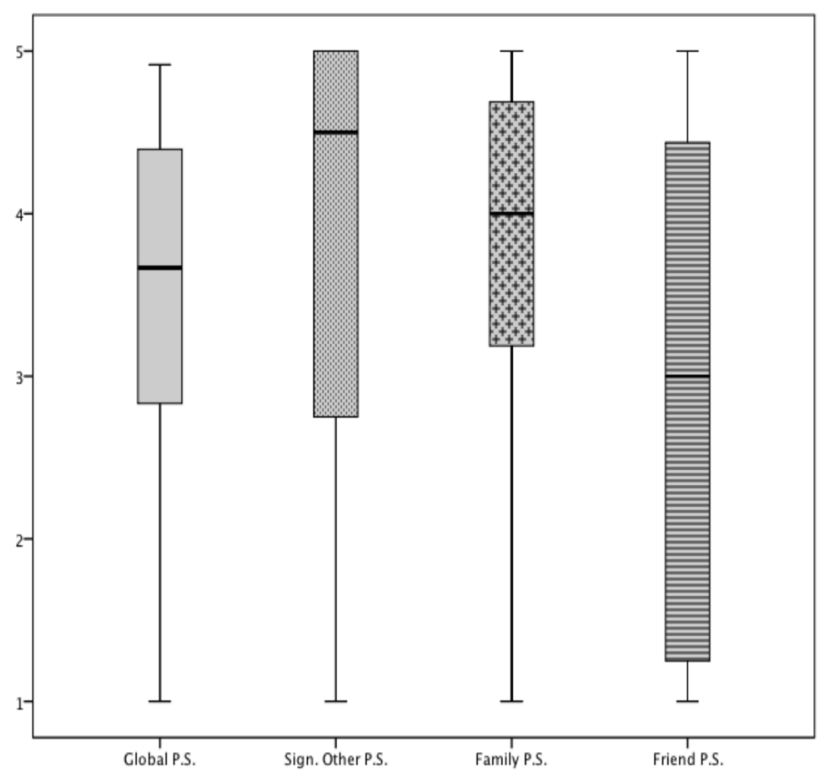

Figure 3. Boxplots of perceived support for global, significant others, family and friends subscales. parents $\left(\mathrm{M}_{3}-\mathrm{M}_{4}\right)$ and duration of single parenthood $\left(M_{1}-M_{4}\right)$. However, the interaction between age and living with parents has a negative significant effect $\left(M_{4}\right)$ : older women living with their parents present an ego network with smaller effective size, and then there are redundant alteri ties and more constraints for egos.

\section{Relationship between perceived and received support}

Besides the received social support, we consider the subjectively perceived support measured through the MSPSS scale. As shown in Figure 3, the values for the family and significant other subscales are generally higher than average values (around four points on a scale with a maximum value of five points), and the value of the friend subscale is similar to the average value (around three points, with a high variability). Using the global scale, single mothers perceived a medium level of support, ranging from 2.7 of the first quartile to 4.5 of the third quartile.

Table 4. Final estimated multiple regression models $\left(M_{1}-M_{3}\right)$ with significant coefficients (at least $\left.p<0,05\right)$, standardised estimated coefficients, $R^{2}$ coefficient for the estimated models. Response variables: global scale of the perceived support [Global], significant other [Significant Other], family [Family] and friend [Friend] subscales. Labels: age [Age]; living with parents [Living]; number of children [Nchil]; network size [NetSi]; kind of alteri [Mother, Father, Partner, New Partner, Workmates, Sons, Friend] and type of support [Financial, Emotional, Informational].

\begin{tabular}{|c|c|c|c|c|c|c|}
\hline Response variable & $M_{1}$ & & $M_{2}$ & & $M_{3}$ & \\
\hline \multirow[t]{4}{*}{ Global } & Nchild & -0.40 & Nchild & -0.43 & Nchild & -0.53 \\
\hline & Mother & 0.51 & Economic & 0.31 & & \\
\hline & & & Instrumental & 0.30 & & \\
\hline & & & Social & 0.23 & & \\
\hline $\mathrm{R}^{2}$ & 0.53 & & 0.57 & & 0.28 & \\
\hline \multirow[t]{4}{*}{ Significant Other } & NetSize & 0.30 & Nchild & & Nchild & -0.37 \\
\hline & Mother & 0.56 & Economic & & & \\
\hline & ExPartner & -0.28 & & & & \\
\hline & Workmates & -0.29 & & & & \\
\hline $\mathrm{R}^{2}$ & 0.48 & & 0.32 & & 0.13 & \\
\hline \multirow[t]{5}{*}{ Family } & Nchild & -0.29 & Nchild & -0.34 & Nchild & -0.30 \\
\hline & Mother & 0.33 & Age & 0.33 & Age & 0.34 \\
\hline & Partner & -0.41 & LivingP & 0.39 & LivingP & 0.45 \\
\hline & & & Economic & 0.43 & & \\
\hline & & & Instrumental & 0.24 & & \\
\hline $\mathrm{R}^{2}$ & 0.44 & & 0.56 & & 0.26 & \\
\hline \multirow[t]{5}{*}{ Friend } & Nchild & -0.65 & Nchild & -0.57 & Nchild & -0.57 \\
\hline & Mother & 0.51 & Age & 0.33 & & \\
\hline & Father & -0.28 & Instrumental & 0.31 & & \\
\hline & Sons & 0.34 & Informational & -0.31 & & \\
\hline & Friends & 0.28 & & & & \\
\hline $\mathrm{R}^{2}$ & 0.65 & & 0.49 & & 0.32 & \\
\hline
\end{tabular}


In order to analyse which ego and network characteristics affect perceived support, a set of regression analyses is performed with the global scale and the three subscales as the response variables. As predictors, we include the ego attributes listed in Table 2, the network size and in turn: the network composition measures (model 1, $M_{1}$ ), the types of support that alteri provide to the ego (model 2, $\mathrm{M}_{2}$ ), and network structure measures (model $3, M_{3}$ ). We adopted the backward selection approach to select the most relevant explanatory variables in each model.

Table 4 shows the final models with the significant coefficients, the standardised coefficients to allow a comparison among the models and the $\mathrm{R}^{2}$ coefficients.

Summing up, the number of children always had a negative effect on perceived support. This is probably due to the fact that the high care giving burden related to having many children makes it impossible for the ego to feel adequately supported. On the contrary, the presence of the mother in the network had a positive impact on all kinds of perceived support. The presence of an ex-partner or a new partner in the network had a negative effect on perceived support from the significant others and the family, respectively. In the first case, this could be related to the caregiver's expectations being disappointed by the ex-partner. A new partner, instead, contributes to enlarging the support network of the single mother and pushes her out of the family network, reducing perceived support from the family. The strong presence of a father had a negative effect on perceived support from friends; in contrast, the presence of sons/daughters (in such a case, we were looking at adult sons/daughters that support the mother in the care of the younger children) had a positive effect on perceived supported from friends.

With respect to the types of support, and the related number of alteri providing it, the types of support that have a positive effect on perceived support were economic support, instrumental support and social companionship. Contrary to what we expected, it seems that emotional support did not significantly affect perceived support. We noted a negative effect of informational support on perceived support from friends. With respect to the single mother's age, it sometimes showed a positive effect on perceived support. As expected, the condition of living with parents had a positive effect on perceived family support.

Finally, according to the network structure measures, they did not present significant effects when associated with ego characteristics.

\section{Discussion and Conclusions}

In the present contribution, social network analysis approach proved to be successful in identifying important characteristics for social support patterns of single mothers as highlighted by both correspondence analysis and regression models. They clarify the strong relationship between the structural and functional content underpinning personal relationships. In addition, SNA provides a worth contribution for measuring certain aspects of social support, stressing the distance between received support and perceived support. As the evidence in our case suggests, the relationship between the two terms cannot be taken for granted.

As highlighted above, single mothers' social support networks support networks are very small in size and are mainly formed by women. The mainly female characterisation of support networks bears out the feminisation of household survival strategy (Sassen, 2002), due to the crucial role of women in making adjustments to cope and survive in the context of adverse economic conditions. This places women under enormous pressure, over-burdening them so that when breakdown events such as a separation or widowhood occur, it makes matters worse.

According to our aims and findings, we note that the main sources of support are represented by kinship members and friends, who represent an extremely important part of the single mother's survival strategy. Specifically, kinship networks continue to play a central role in meeting the basic needs of single mothers, including looking after children, giving small sums of money and so on. In many cases, friends also share similar conditions of job and economic instability. They offer emotional support and social companionship but not much else. Moreover, due to the fragility of the local welfare system and the lack of income support schemes, social workers can support single mothers by offering them emotional support and helping them to navigate the social and health services available, giving advice or information. In many cases, however, they cannot help them to improve their lives or to set up active routes out of poverty. Single mothers are occasionally supported by other professional caregivers, such as those in parishes or volunteers in nonprofit organisations, but this support is patchy and does not represent an efficient means of coping. Thus, these networks are unable to give any serious economic help or offer upward mobility opportunities. This implies that these single mothers risk being entrapped in hardship, 
not only because family resources are poor in quality, but because the support provided by the immediate family has often been exchanged for a higher investment by single mothers in domestic tasks and in-kind services -which hinders their social relationships and their chances of better employment opportunities, increasing the risk of that their condition in life will decline over time. It is not by chance that older women living with their parents have smaller networks, mainly composed by redundant alteri.

However, in the absence of the immediate family, and specifically the mother, the degree of perceived social isolation increases, and life conditions become harder for the single mother.

The relationship between network composition and support content shows the persistence of an unequal sharing of family functions between genders, according to a male bread-winner model. As we know, this model assigns to men (fathers, brothers or sons) the role of family provider and to women the caregiving burden. The role of family provider seems to be played only by the male family members. The actual fathers are missing and, in such cases, the presence of a new partner seems to take single mothers away from their family support networks. Arguably, this may be related to the need of the immediate family to optimise, as efficiently as possible, the intrahousehold redistribution of scarce resources.

Of course, given that this is one case study limited to a small sample of single mothers in Naples, caution in the generalizability of results is merited. However, we note that this is one of the first studies of this kind, and the findings encourage us in further work.

This project might benefit from including complementary qualitative data on women's experiences, perspectives and meaning-making about their own lives.

In addition, as a further analysis step, we aim to benefit from the achievements in the field of hierarchical linear modelling in order to take into account the unexplained variability between ties and ego and the cross-level interactions between these two levels of analysis (Snijders et al., 1995; Van Duijn et al., 1999). This approach could be used to disentangle the complex structure of the data to guide the development of new research questions.

\section{References}

Agneessens, F., Waege, H., and Lievens, J. (2006) 'Diversity in social support by role relations: A typology'. Social networks, 28(4): 427-441.

Belle, D. (1982) Lives in stress: Women and depression. Beverly Hills, CA: Sage.
Berkman, L. (1986) 'Social networks, support and health: Taking the next step forward'. American Journal of Epidemiology, 123(4): 559-562.

Berkman, L.F., Glass, T., Brissette, I., Seeman, T.E. (2000) 'From social integration to health: Durkheim in the new millennium'. Social Science and Medicine, 51(6): 843-857.

Borgatti, S. (2006) E-net software for the analysis of ego-network data. Needham, MA: Analytic Technologies.

Borgatti, S.P., Everett, M.G., and Johnson, J.C. (2013) Analyzing Social Networks. London: Sage.

Burt, R.S. (1992) Structural Holes. Cambridge, MA: Harvard University Press.

Cassel, J. (1976) 'The contribution of the social environment to host resistance'. American Journal of Epidemiology, 104: 107-123.

Cobb, S. (1976) 'Social support as a moderator of life stress'. Psychological Medicine, 38: 300-314.

Cohen, S., and Wills, T.A. (1985) 'Stress, social support, and the buffering hypothesis'. Psychological bulletin, 98(2): 310-357.

Due, P., Holstein, B., Lund, R., Modvig, J. and Avlund, K. (1999) 'Social relations: network, support and relational strain'. Social Science and Medicine, 48: 661-673.

Eckenrode, J., and Hamilton, S. (2000) 'One-to-one support interventions: Home visitation and mentoring'. In Cohen, S., Underwood, L.G. and Gottlieb, B.H. (eds.) Social support measurement and intervention: a guide for health and social scientists, pp. 246-277. New York: Oxford University Press.

Eurostat (2013). Household composition, poverty and hardship across Europe. Statistical working papers. Publications Office of the European Union.

Eurostat (2015). People at risk of Poverty and Social Exclusion [Data file]. Retrieved from http://ec.europa.eu/eurostat/en/data/ database.

Fouarge, D., and Layte, R. (2005) 'Welfare regimes and poverty dynamics: the duration and recurrence of poverty spells in Europe'. Journal of Social Policy, 34(3): 407-426.

Gambardella, D., and Morlicchio, E. (2005). Familismo forzato. Scambi di risorse e coabitazione nelle famiglie povere a Napoli. Roma: Carocci.

Geens, N., and Vandenbroeck, M. (2014) 'The (ab)sense of a concept of social support in parenting research: a social work perspective'. Child and Family Social Work, 19: 491-500.

Gottlieb, B.H., and Bergen, A.E. (2010) 'Social support concepts and measures'. Journal of Psychosomatic Research, 69(5): 511-520.

Greenacre, M., and Blasius, J. (2006) Multiple correspondence analysis and related methods. London: Chapman and Hall, CRC Press.

Gregory, R.P., Pierce, B.R., and Sarason, I.G. (1996) Handbook of Social Support and Family. New York: Springer.

Halgin, D.S., and Borgatti, S.P. (2012) 'An introduction to personal network analysis and Tie Churn statistics using E-NET'. Connections, 32(1): 37-48.

Henly, J.R., Danziger, S.K., and Offer, S. (2005) 'The contribution of social support to the material well-being of low-income families'. Journal of Marriage and Family, 67(1): 122-140.

Hlebec, V., and Kogovšek, T. (2013). Different approaches to measure ego-centered social support networks: a meta-analysis. Quality and Quantity, 47(6): 3435-3455.

Hlebec, V., Mrzel, M., and Kogovšek, T. (2012) 'Assessing social support networks in cross-national comparative surveys: measurement issues'. Quality and Quantity, 46(5): 1431-1449. 
lacovou, M., and Skew A.J. (2011) 'Household composition across the new Europe: Where do the new member states fit in?' Demographic Research, 25: 465-490.

Kogovšek,T., Ferligoj, A., Coenders, G., and Saris, W.E. (2002) 'Estimating the reliability and validity of personal support measures: full information ml estimation with planned incomplete data'. Social networks, 24(1): 1-20.

Krackhardt, D., and Stern, R.N. (1988) 'Informal networks and organizational crises: An experimental simulation'. Social psychology quarterly, 51(2): 123-140.

Lin, N. (2002) Social capital: A theory of social structure and action. Cambridge, MA: Cambridge University Press.

Marsden, P.V. (2011) 'Survey methods for network data'. In Scott, J. and Carrington, P.J. (eds.) The SAGE handbook of social network analysis, pp. 370-388. London: SAGE publications.

Miller, A.J. (1984) 'Selection of Subsets of Regression Variables'. Journal of the Royal Statistical Society. Series A., 147: 389-425.

Morlicchio, E. (2005) 'Challenging the family: the new urban poverty in Southern Europe'. In Kazepov, Y. (ed.) Cities in Europe: Changing contexts, local arrangements, and the challenge to urban cohesion, pp. 277-300. Oxford: Blackwell Publishing.

Naldini, M. (2003) Family in the Mediterranean Welfare States. Oxon: Routledge.

O'Reilly, P. (1988) 'Methodological Issues in Social Support and Social Network Research'. Social Science and Medicine, 26: 863-873.

Ranci, C. (2012) Social Vulnerability in Europe: The New Configuration of Social Risks. Basingstoke,UK: Palgrave Macmillan.

Rollins, B. C., and Thomas, D.L. (1979) 'Parental support, power, and control techniques in the socialization of children'. In Burr, W. R., Hill, R., Nye, F. I.and Reiss, I. L. (eds.) Contemporary theories about the family, pp. 317-364. New York: Free Press.

Ruspini, E. (2011) 'Single mothers'. In Zeiss Stange, M., Oyster, C.K and Sloan, J.E. (eds.) Encyclopedia of Women in Today's World, pp. 1353-1356. Thousand Oaks, CA: Sage.
Saraceno, C. (2002) Social assistance dynamics in Europe: national and local poverty regimes. Bristol: The Policy Press.

Sassen, S. (2002) 'Counter-geographies of globalisation: feminisation of survival'. In Saunders, K. (ed.) Feminist post-development thought,pp. 89-104. London: Zed Books.

Smith, K.P. and Christakis, N.A. (2008) 'Social Networks and Health'. Annual Review of Sociology, 34: 405-429.

Snijders, T., Spreen, M., and Zwaagstra, R. (1995) 'The use of multilevel modeling for analysing personal networks: Networks of cocaine users in an urban area'. Journal of quantitative anthropology, 5(2): 85-105.

Stack, C.B. (1975) All our kin: Strategies for survival in a black community. New York: Basic Books.

Stansfeld, S., and Khatib, Y. (2011) 'Social Support and Social Networks'. In: Nriagu, J.O. (Ed.) Encyclopedia of Environmental Health, volume 5, pp. 119-123. Burlington: Elsevier.

Symonds, P. (1939) The psychology of parent-child relationships. New York: Appleton-Century-Crofts.

Tietjen, A.M. (1985) 'The social networks and social support of married and single mothers in Sweden'. Journal of Marriage and the Family, 47(2): 489-496.

Van Duijn, M.A., Van Busschbach, J.T. and Snijders, T.A. (1999) 'Multilevel analysis of personal networks as dependent variables'. Social Networks, 21(2): 187-210.

Vaux, A. (1988) Social support: Theory, research, and intervention. New York: Praeger publishers.

Wasserman, S., and Faust, K. (1994) Social Network Analysis: Methods and Applications. Cambridge: Cambridge University Press

Wellman, B (2007) 'The network is personal: Introduction to a special issue of social networks'. Social networks, 29(3): 349-356.

Zimet, G.D., Dahlem, N.W., Zimet, S.G., and Farley, G.K. (1988) 'The multidimensional scale of perceived social support'. Journal of personality assessment, 52(1): 30-41. 